\title{
Development of a New Dosage Form of Naproxen
}

\author{
DOI: $10.17691 /$ stm2017,9.4.23
}

Received April 18, 2017

Yu. Ye. Lebedeva, PhD Student, Pharmaceutical Faculty ${ }^{1}$;

E.R. Valeeva, PhD Student, Pharmaceutical Faculty';

P.G. Zabolotnaya, Chief Development Officer';

Zh.M. Kozlova, PhD, Associate Professor, Chair of Pharmaceutical Technology ${ }^{1}$

1.M. Sechenov First Moscow State Medical University, 8/2 Trubetskaya St., Moscow, 119991,

Russian Federation;

2MFPStandard Ltd., office 147, building 1, 64 Shipilovskaya St., Moscow, 115682, Russian Federation

The aim of the study was to create a new dosage form of naproxen - granules for rapid dissolution in the oral cavity, also to develop their optimum composition and drug formulation.

Materials and Methods. The active ingredient: naproxen substance; excipients: lactose monohydrate, mannitol 100 SD (fillers), polyvinylpyrrolidone Kollidon CL (a disintegrant), sodium hydrogen carbonate and citric acid (gas-forming agent).

Moisture-activated dry granulation with subsequent addition of citric acid was used to produce granules. Alcohol in different concentrations $(5,10,20$, and $30 \%)$ served as granulating liquid.

Results. There has been developed the composition and drug manufacturing technology of the new dosage form of naproxen granules for rapid dissolution in the oral cavity. It has been established experimentally that granules obtained with the use of $20 \%$ alcohol have the most favorable technological characteristics. Quality assessment was carried out in accordance with the State Pharmacopoeia XIII.

Conclusion. There has been obtained a new easy-to-use dosage form of naproxen with a high safety profile.

Key words: granules for dissolution in the oral cavity; naproxen; nonsteroidal anti-inflammatory drugs; moisture-activated dry granulation.

Finding the most effective and safe drugs for pain management is one of the urgent tasks in medicine. Drugs classified as nonsteroidal anti-inflammatory drugs (NSAIDs) are important means for pain management in modern pharmaceutical market. They have been widely used in various fields of medicine. Their administration is advisable in all the cases when pain is caused by tissue damage or inflammatory process.

In 1899, the first representative of NSAID group, aspirin, appeared on the European pharmaceutical market. That was when the era of effective pain relief began. Eventually, there were created a large number of analgesic medications with various chemical structure. Naproxen was synthesized at the same time as diclofenac and appeared in the pharmaceutical market two years later, in 1976. The first clinical trials began in the mid-70s and proved the drug efficacy in all clinical cases when the use of NSAIDs for pain (from migraine to surgical one) was appropriate. It successfully stood comparison with the related drugs of various chemical structures such as aspirin, indomethacin, piroxicam, paracetamol, etc. In all studies it was no inferior to the control drugs or beat them in efficiency and had better overall tolerance. Therapeutic efficacy of naproxen was confirmed in anesthesia practice: after surgery it had a pronounced analgesic and opioid-saving effect.
In addition to the obvious advantages in terms of efficacy, naproxen has demonstrated a high safety profile, in particular, low risk of cardiovascular complications. This is especially relevant in the context of application in geriatric practice due to the fact that most elderly patients have concomitant diseases of the cardiovascular system. Naproxen produces effect similar to aspirin: it reliably blocks cyclooxygenase-1 and inhibits the synthesis of thromboxane A2 for a long time. According to clinical test data, this effect has been observed even at low doses of naproxen [1].

Other clinical tests have shown that naproxen is one of the most successful medications for emergency pain relief. Derry et al. [2] carried out meta-analysis of 15 randomized clinical trials $(n=1,509)$ evaluating the efficacy of a single dose of naproxen to relieve acute pain. It proved to be significantly superior to comparator drugs. Advantages of naproxen as a fastacting analgesic become especially obvious when it is compared to opioids. Simmons et al. [3] studied the efficacy of naproxen and co-formulated opioid drug dextropropoxyphene in combination with paracetamol in 184 individuals with sports injuries. By the end of 7-day treatment period naproxen showed not only the best result in terms of pain relief and function restoration, but a significantly lower incidence of adverse effects.

For contacts: Yuliya Y. Lebedeva, e-mail: julia.lebedeva02@gmail.com 
The most frequent side effect of NSAIDs is damage to the upper gastrointestinal tract mucosa. According to Castellsague et al. [4] who carried out meta-analysis of 28 epidemiologic studies during $1980-2011$ to estimate development of gastrointestinal tract complications associated with the use of various NSAIDs, celecoxib, aceclofenac, and ibuprofen appeared to have the lowest risk. The risk of gastrointestinal bleeding appeared to be nearly similar between diclofenac, meloxicam, nimesulide, ketoprofen, naproxen, and indomethacin. Therefore, concomitant administration of naproxen and proton pump inhibitors, particularly pantoprazole, is widespread in conventional clinical practice [5].

Naproxen has been successfully used in 25 countries of Europe for more than 40 years, remaining one of the most commonly prescribed medicines. Today, naproxen drugs exist on the pharmaceutical market only in the form of pills, film-coated tablets and rectal suppositories [6]. However, the granulated form is known to require the minimum time for achieving the maximum concentration in blood plasma and absorption in the oral cavity greatly accelerates the onset of therapeutic effect [7, 8]. It was shown at the early stage of drug usage that oral bioavailability of insoluble naproxen and naproxen in a soluble salt form is similar in dogs, introduction of naproxen in suspension providing a shorter absorption time [9]. Exceedingly high risk of ulcerogenic effect can also be smoothed by creating a granulated form thereby increasing safety profile. This pharmaceutical dosage form is easy to use: the patient can use the drug not only in aqueous solution but also without prior dissolution at any time. Besides, this pharmaceutical form is notable for high bioavailability, ease of manufacture and storability.

Naproxen is a white, crystalline powder practically water-insoluble, soluble in $96 \%$ alcohol and methanol, slightly soluble in ether. Bulk density is $0.287 \pm 0.008 \mathrm{~g} /$ $\mathrm{ml}$, tapped density is $0.435 \pm 0.008 \mathrm{~g} / \mathrm{ml}$, which suggests that the active substance has poor flowability [10]. Poor flowability of the substance, difficulty in achieving uniform distribution of all pressed mixture components and other unsatisfactory technological characteristics require careful consideration of possible compositions as well as the optimum technology for formulation of naproxen granules.

The aim of the investigation was to create a new dosage form of naproxen - granules for rapid dissolution in the oral cavity, to develop their optimum composition and drug formulation.

Materials and Methods. The object of the study was naproxen substance and excipients such as lactose monohydrate, mannitol $100 \mathrm{SD}$, polyvinylpyrrolidone Kollidon CL, sodium hydrogen carbonate and citric acid. Lactose monohydrate 100 mesh selected as the main filler has a number of obvious advantages: low cost and high flowability, while mannitol has a sweet taste. Both components exhibit low hygroscopicity thereby reducing the risk of moisture absorption. Kollidon $\mathrm{CL}$ served as a disintegrant to form a more uniform suspension by dissolving the granules in water. Sodium hydrogen carbonate and citric acid were gas-forming agents.

Naproxen tablets are used in two therapeutic doses: $250 \mathrm{mg}$ and $500 \mathrm{mg}$. Dosage of $250 \mathrm{mg}$ was chosen as the most convenient in accordance with the approved drug dosing regimen.

The traditional wet granulation method, as well as separate moisture-activated dry granulation, were used to produce granules. Excipients play an important role in granulation: granulating (binding) fluids determine the quality of the material being granulated and the resulting granules (strength, disintegration capacity, dissolution) [11]. Aqueous solutions of ethyl alcohol in various concentrations $(5,10,20$, and $30 \%)$ frequently used in wet granulation were studied [12].

Using the minimum amount of moisturizing agent in moisture-activated dry granulation allows reducing the adverse impact of moisture on pharmaceutical substance and the excipients to avoid prolonged heat exposure when drying and obtain a homogeneous granulate without subsequent drying.

To determine technological characteristics of mass for granulation and the obtained granules, the following methodology was used.

1. Degree of flowability was determined using the ERWEKA GTL apparatus (ERWEKA $\mathrm{GmbH}$, Germany) according to the methods described in State Pharmacopoeia XIII - SP XIII (Pharmacopoeia General Chapter (PGC) "Degree of powder flowability").

2. Appearance was evaluated organoleptically and microscopically (microscope MIKRAN-2; TekhOborudovanie, Russia).

3. The size of the obtained granules was evaluated by screen analysis in accordance with SP XIII (PGC "Screen analysis").

4. The test for "disintegration capacity" was carried out for effervescent granules in accordance with SP XIII (PGC "Granules") using the following method. A single dose of granules was placed in a beaker containing $200 \mathrm{ml}$ of water, intense effervescence being observed. Granules were considered capable of disintegration if they either dissolved or dispersed in water after gas liberation came to an end. The test was carried out in 5 repetitions. Granules stood the test if each of the 5 doses dissolved within 5 min.

5. The test for "dissolution" was not carried out as, in accordance with SP XIII for granules whose disintegration time does not exceed $5 \mathrm{~min}$, this indicator is not assessed.

When developing the optimum composition and formulation technology the following equipment was used:

powder flowability testing system ERWEKA GTL (ERWEKA GmbH, Germany);

ED153 analytical balance (Sartorius, Germany); ED 8201 analytical balance (Sartorius, Germany); mixer granulator Glatt TMG (Glatt GmbH, Germany); microscope MIKRAN-2 (TekhOborudovanie, Russia). 
Results and Discussion. In the framework of this experiment, there were investigated physicochemical properties of active substance, various functional groups of excipients, pharmaceutical formulation technologies. Qualitative characteristics of the obtained granules with various pharmaceutical compositions were studied. The following compositions were selected as the most satisfactory (see the Table).

There was carried out work on finding technological solutions for preparing granules by both traditional method and moisture-activated dry granulation. The choice of granulation mode was based on the results of preliminary tests which allowed us to select the following technology for obtaining granules.

Pre-screened ingredients (naproxen, lactose monohydrate, mannitol 100 SD, Kollidon CL and sodium hydrogen carbonate) were placed in the vessel of universal tabletop mixer granulator Glatt TMG where the components were mixed for $15 \mathrm{~min}$ to achieve homogeneity. At the next stage, a moisturizing agent was introduced by spraying finely atomized granulating liquid at continuous stirring for $20 \mathrm{~min}$. We used 5, 10, 20 , and $30 \%$ alcohol as granulating fluid in an amount of $5-10 \%$ of granulated mixture weight. At the end the

The composition of granules under study

\begin{tabular}{lccc}
\hline \multirow{2}{*}{ Components } & \multicolumn{3}{c}{ Quantity per 10 doses (powder) (g) } \\
\cline { 2 - 4 } & Composition 1 & Composition 2 & Composition 3 \\
\hline Naproxen & 2.5 & 2.5 & 2.5 \\
\hline Lactose monohydrate & 10.7 & 1.5 & 1.5 \\
\hline Mannitol 100 SD & - & 9.2 & 9.2 \\
\hline Kollidon CL (polyvinylpyrrolidone) & 0.3 & - & 0.3 \\
\hline Sodium hydrogen carbonate & 1.5 & 1.5 & 1.5 \\
\hline Citric acid & 1.5 & 1.5 & 1.5 \\
\hline
\end{tabular}

citric acid was added. As a result, there were produced granules, representing agglomerates of mixture particles requiring no subsequent drying [13].

Microscopic analysis of the obtained granules showed that granules of composition 1 had poor characteristics at all alcohol concentrations, their shape was far from spherical, which could lead to deterioration of flowability of the obtained granules and have a negative impact on drug appearance [14] (Figures 1, 2).

When studying disintegration capacity of composition 2, the prepared suspension was found to precipitate quickly at any alcohol concentration, the particles being unevenly distributed in the necessary volume. It was concluded that the obtained result was associated with the absence of disintegrant (Kollidon $\mathrm{CL}$ ) in the composition.

All tests conducted on the granules obtained from composition 3 showed good results at any alcohol concentration (Figure 3). Microscopic analysis revealed that the resulting granules had almost perfect spherical shape, equal size, which determined favorable properties of the produced granules. Microscopic analysis showed that the obtained granules demonstrated better results when 20 and $30 \%$ alcohol was used (Figure 4).

Disintegration of granules obtained by this method occurs in $200 \mathrm{ml}$ of water within $20 \mathrm{~s}$, a uniform suspension forming due to effervescence. The obtained granules can also be used without prior dissolution in water by pouring the dosed powder contained in $1 \mathrm{~g}$ paper bags into the mouth, which is definitely convenient for consumers.

Thus, development of naproxen granules intended for dissolution in the oral cavity is appropriate and relevant as it contributes to expanding the Russian pharmaceutical market of painkillers with
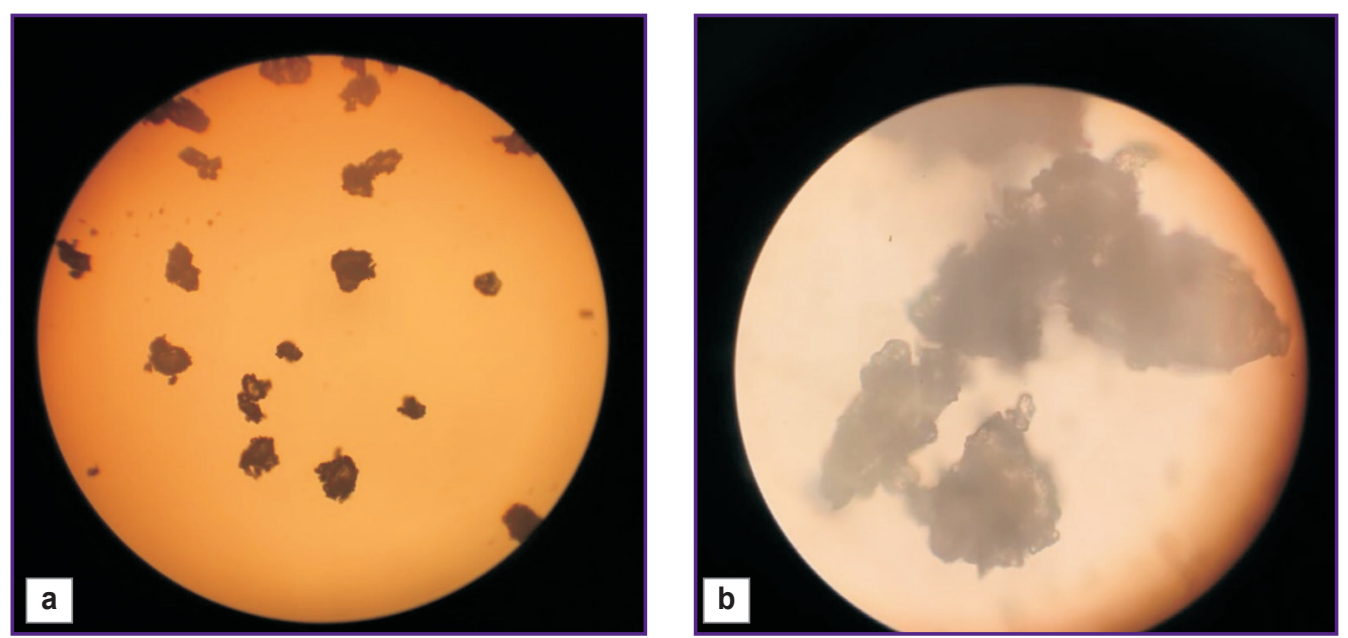

Figure 1. Composition 1 of the developed granules $+5 \%$ alcohol:

(a) $\times 100$; (b) $\times 400$ 

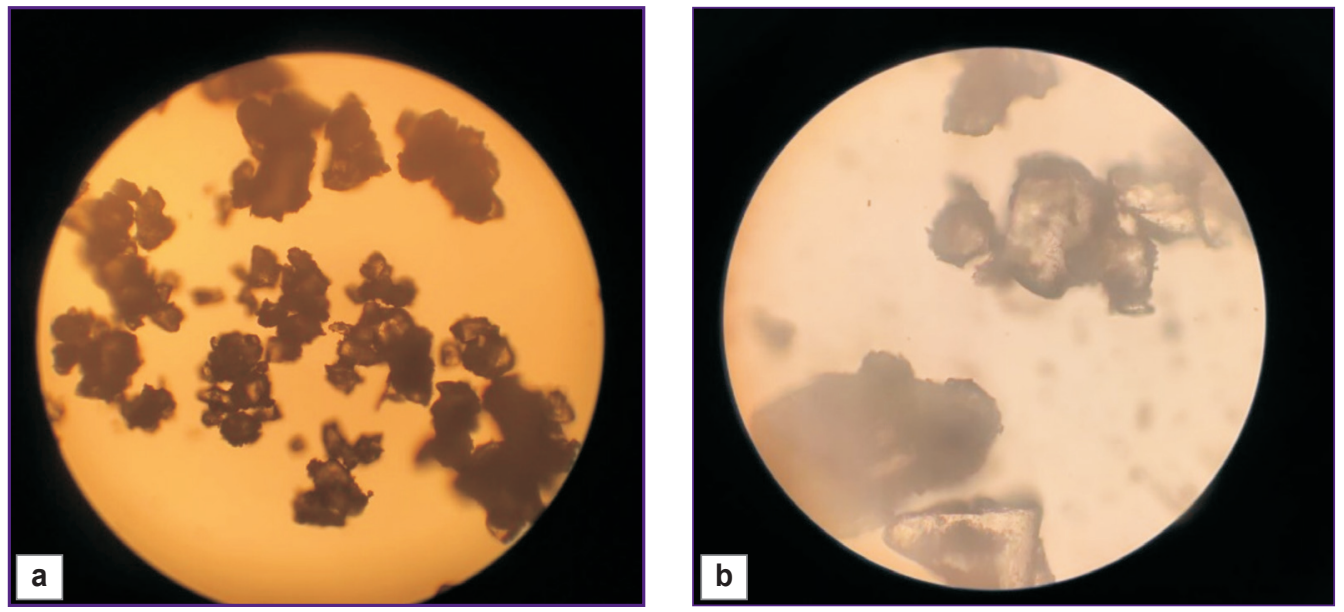

Figure 2. Composition 1 of the developed granules $+\mathbf{2 0} \%$ alcohol:

(a) $\times 100$; (b) $\times 400$
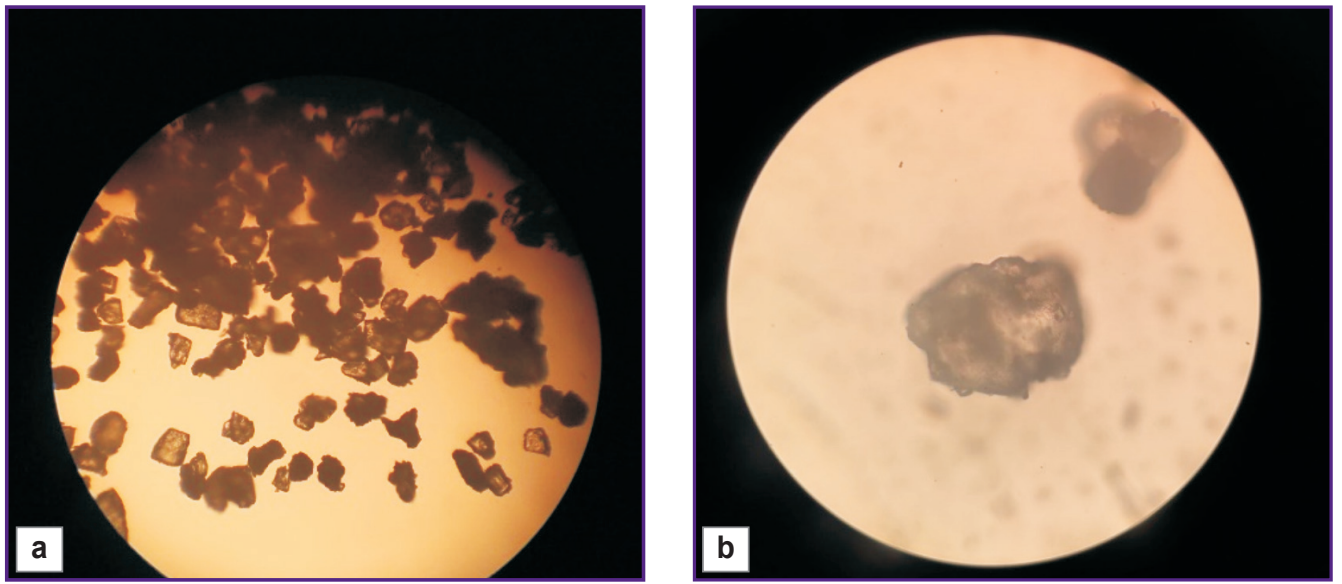

Figure 3. Composition 3 of the developed granules $+5 \%$ alcohol:

(a) $\times 100$; (b) $\times 400$
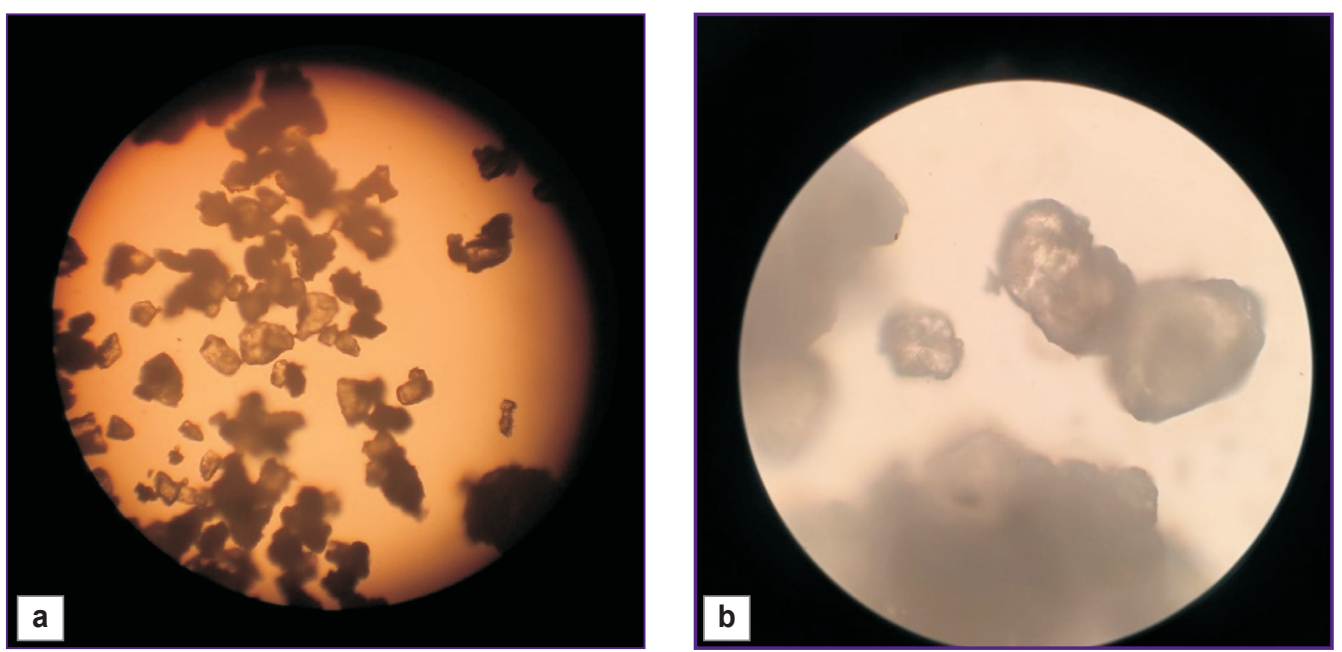

Figure 4. Composition 3 of the developed granules $+20 \%$ alcohol:

(a) $\times 100$; (b) $\times 400$ 
the medicinal product in a dosage form unrepresented in this segment.

Conclusion. Creating granule dosage form of naproxen provides the possibility to increase safety profile of the drug under study by reducing ulcerogenic effect.

In addition, this dosage form can improve compliance of patients due to its ease of use.

Study Funding. This study was not supported by any financial sources.

Conflict of Interests. The authors have no apparent or potential conflict of interests related to publication of this article and report on the contribution of each author: Zh.M. Kozlova was responsible for the development of concept and design, data analysis and interpretation, verification of critically important intellectual content, final approval of the manuscript; Yu.Ye. Lebedeva was responsible for the development of concept and design, setting up experiments, data analysis and interpretation, verification of critically important intellectual content, final approval of the manuscript; E.R. Valeeva was responsible for the development of concept and design, data analysis and interpretation, verification of critically important intellectual content; P.G. Zabolotnaya was responsible for setting up experiments, data analysis and interpretation, verification of critically important intellectual content.

\section{Reference}

1. Leung G.J., Rainsford K.D., Kean W.F. Osteoarthritis of the hand II: chemistry, pharmacokinetics and pharmacodynamics of naproxen, and clinical outcome studies. J Pharm Pharmacol 2014; 66(3): 347-357, https://doi. org/10.1111/jphp.12165.

2. Derry C., Derry S., Moore R.A., McQuay H.J. Single dose oral naproxen and naproxen sodium for acute postoperative pain in adults. Cochrane Database Syst Rev 2009; 1: CD004234, https://doi.org/10.1002/14651858. cd004234.pub3.

3. Simmons R.L., Owen S., Abbott C.J., BouchierHayes T.A., Hunt H.A. Naproxen sodium and paracetamol/ dextropropoxyphene in sports injuries - a multicentre comparative study. $\mathrm{Br} J$ Sports Med 1982; 16(2): 91-95, https://doi.org/10.1136/bjsm.16.2.91.
4. Castellsague J., Riera-Guardia N., Calingaert B., Varas-Lorenzo C., Fourrier-Reglat A., Nicotra F., Sturkenboom M., Perez-Gutthann S. Individual NSAIDs and upper gastrointestinal complications: a systematic review and meta-analysis of observational studies (the SOS project). Drug Saf 2012; 35(12): 1127-1146, https://doi.org/10.1007/ BF03261999.

5. Karateev A.E., Alekseeva L.I., Anikin S.G. A combination of naproxen and esomeprazole: analgesic therapy on balancing cardiovascular and gastrointestinal risks. Sovremennaya revmatologiya 2013; 1: 82-93.

6. The State Registry of Medicines. URL: http://grls. rosminzdrav.ru/.

7. Ipatova O.M., Torkhovskaya T.I., Medvedeva N.V., Prozorovsky V.N., Ivanova N.D., Shironin A.V., Baranova V.S., Archakov A.I. Bioavailability of oral drugs and the methods for its improvement. Biochemistry (Moscow) Supplement. Series B: Biomedical Chemistry 2010; 4(1): 82-94, https://doi. org/10.1134/s1990750810010117.

8. Nguyen S., Hiorth M. Advanced drug delivery systems for local treatment of the oral cavity. Ther Deliv 2015; 6(5): 595-608, https://doi.org/10.4155/tde.15.5.

9. Runkel R.A., Kraft K.S., Boost G., Sevelius H., Forchielli E., Hill R., Magoun R., Szakacs J.B., Segre E. Naproxen oral absorption characteristics. Chem Pharm Bull (Tokyo) 1972; 20(7): 1457-1466, https://doi.org/10.1248/ cpb.20.1457.

10. Kozlova Zh.M., Khalikova E.R., Milova V.M. Development of the optimal composition of orally disintegrated naproxen tablets. Novaya nauka: teoreticheskiy i prakticheskiy vzglyad 2016; 6-3: 185-189.

11. Gosudarstvennaya farmakopeya Rossiyskoy Federatsii. T. 2 [The State Pharmacopoeia of the Russian Federation. Vol. 2]. Moscow: 2015; 215 p.

12. Alekseev K.V., Kedik S.A., Blynskaya E.V., Alekseev V.K., Maslennikova N.V. Farmatsevticheskaya tekhnologiya. Tabletki [Pharmaceutical technology. Tablets.]. Moscow: ZAO IFT; 2015; 672 p.

13. Latypova G.M., Davletshina R.Y., Kataev V.A., Romanova Z.R. Obtaining of granules on the basis of the extract from primula officinalis herb. Izvestiya Samarskogo nauchnogo tsentra Rossiyskoy akademii nauk 2011; 13(5-3): 64-67.

14. Emshanova S.V., Zuev A.P., Sadchikova N.P. Drug particle shape and size control: a necessary factor for high-quality drug production. Pharmaceutical Chemistry Journal 2007; 41(1): 41-49, https://doi.org/10.1007/s11094007-0010-9. 